\title{
Kinematic and dynamic modeling of a 3gdl robot for educational purposes
}

\section{Modelado cinemático y dinámico de un robot de 3gdl con propósitos didácticos}

REYES-GONZÁLEZ, Aleyda Irene, ORTIZ-SIMÓN, José Luis, AGUILERA-HERNÁNDEZ, Martha Isabel and ROJO-VELÁZQUEZ, Gustavo Emilio

Tecnológico Nacional de México / Instituto Tecnológico de Nuevo Laredo

ID $1^{\text {st }}$ Author: Aleyda Irene, Reyes-González / ORC ID: 0000-0003-4188-6875

ID $1{ }^{\text {st }}$ Coauthor: José Luis, Ortiz-Simón / ORC ID: 0000-0001-6548-3849, CVU CONACYT ID: 209883

ID $2^{\text {nd }}$ Coauthor: Martha Isabel, Aguilera-Hernández / ORC ID: 0000-0001-8127-190X, Researcher ID Thomson: S4724-2018, CVU CONACYT ID: 19115

ID $3^{\text {rd }}$ Coauthor: Gustavo Emilio, Rojo-Velázquez / ORC ID: 0000-0002-7792-1436, Researcher ID Thomson: S-47242018, CVU CONACYT ID: 26367

DOI: $10.35429 /$ JCSI.2020.18.6.1.7

Received September 30, 2020; Accepted December 30, 2020

\begin{abstract}
The following article presents the process to obtain the kinematic and dynamic model of a Cartesian robot with 3 degrees of freedom. The robot that is used was designed for educational purposes, it allows two linear movements and one angular. The kinematic model has two forms, direct and inverse, the first provides the final position of the robot if desired values are given to each of the robot's joints, the second provides the values of the joints if there are desired values for the effector final. On the other hand, the obtaining of the dynamic model is presented in detail, which obtains the torques and forces necessary for the robot to be able to move to a specific point. The procedure includes kinematic analysis using Denavit-Hartenberg parameters and dynamic analysis using Jacobeans. As a result, responses obtained from a Simulink model are presented that show the behavior of the developed models.
\end{abstract}

Direct kinetics, Inverse kinetics, Dynamic model

\begin{abstract}
Resumen
En este artículo se presenta el proceso para obtener el modelo cinemático y dinámico de un robot cartesiano de 3 grados de libertad. El robot que se utiliza fue diseñado con propósitos didácticos, este permite dos movimientos lineales y uno angular. El modelo cinemático presenta dos formas, directo e inverso, el primero proporciona la posición final del robot si se le dan valores deseados a cada una de las articulaciones del robot, el segundo proporciona los valores de las articulaciones si se tienen valores deseados para el efector final. Por otro lado, se presenta a detalle la obtención del modelo dinámico, el cual obtiene los torques y fuerzas necesarias para que el robot pueda desplazarse a un punto especifico. El procedimiento incluye análisis cinemático mediante parámetros DenavitHartenberg y análisis dinámico mediante Jacobianos. Como resultado, se presentan respuestas obtenidas de un modelo en Simulink que muestra el comportamiento de los modelos desarrollados.
\end{abstract}

Cinemática directa, Cinemática inversa, Modelo dinámico

Citation: REYES-GONZÁLEZ, Aleyda Irene, ORTIZ-SIMÓN, José Luis, AGUILERA-HERNÁNDEZ, Martha Isabel and ROJO-VELÁZQUEZ, Gustavo Emilio. Kinematic and dynamic modeling of a $3 \mathrm{gdl}$ robot for educational purposes. Journal of Computational Systems and ICTs. 2020. 6-18:1-7

*Correspondence to Author (e-mail: aleydare.ar@gmail.com)

$\dagger$ Researcher contributing as first author. 


\section{Introduction}

Mechatronics engineering in its development includes the subject of robotics, which offers knowledge such as the design of systems with $n$ degrees of freedom, kinematic modeling, knowing the energy consumption that the system will require and also control methods for positioning.

Although there is a theoretical basis to carry out analysis of robotic systems in a systematic way, the current literature uses similar structures in its development, leaving doubts that can be cleared in another way if other examples were available, in addition to exposing problems to which it can be tackled at some point in development.

This article will explicitly develop the procedure to obtain kinematic and dynamic mathematical models of a structure different from what is normally seen. All this, raised from a didactic point of view.

\section{Mechanical design}

The design of the robot to be studied is of four links and three joints in order to have a demonstrative system with two prismatic joints and another angular one.

Referential frames and axes, as well as their respective centers of mass, were assigned according to the Denavit-Hartenberg convention. Figure 1.

\section{Direct kinematics}

Direct kinematics consists of finding the value of the final position of the robot, this solution is a function of the joint values, that is, the translational or rotational value of the joints. At present there are different methods to solve this problem, but in this case the homogeneous transformation matrices were used, using the Denavit-Hartenberg systematic representation method.

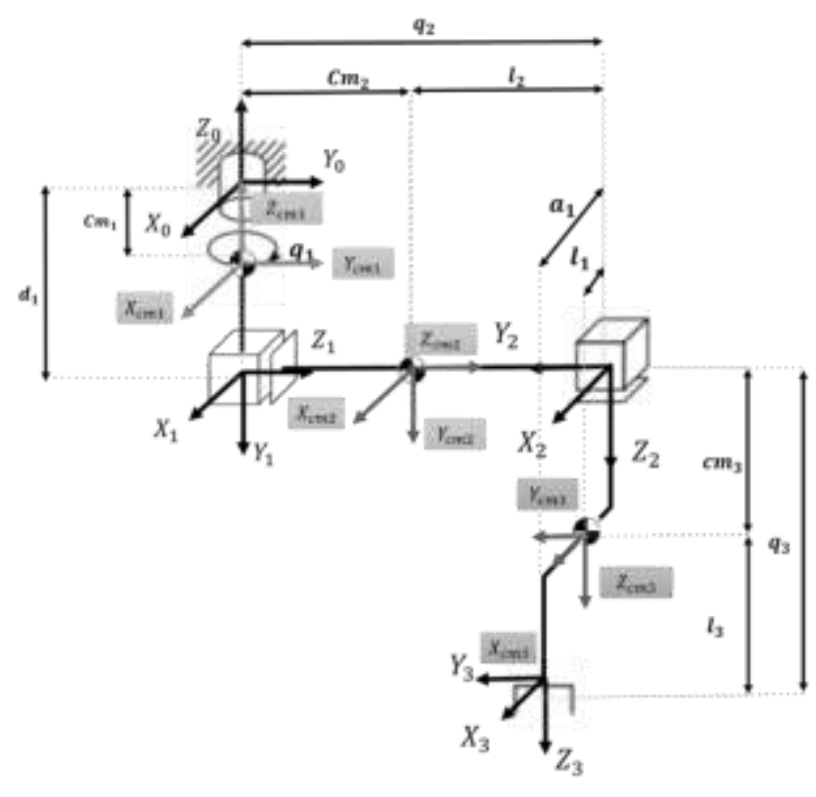

Figure 1 Robot RPP

Source: Own Elaboration

The Denavit-Hartenberg representation is replaced in the homogeneous transformation matrix $T_{i}{ }^{i-1}$, it contains information regarding the position and orientation of the reference frame attached to the $i$ link of the manipulator in relation to the reference frame of the i-1 connection; with this, the matrix ${ }_{1}^{0} T$ represents the position and orientation of the robot's $\mathrm{O}_{1}$ coordinate system with respect to the $\mathrm{O}_{0}$ coordinate system, if $\mathrm{O}_{0}$ is placed on the manipulator axis and $\mathrm{O}_{1}$ at the end of a link, the matrix ${ }_{1}^{0} T$ represents the position of $\mathrm{O}_{1}$ referenced to the robot's fixed coordinate system. In this way, the matrix ${ }_{i}^{0} T$, in which $\mathrm{n}$ is the degree of freedom, it is the one that represents the final position of the manipulator with respect to the reference system; This matrix is commonly called $\mathrm{T}$ and is represented by the following equations:

$$
\begin{aligned}
& T={ }_{i}^{0} T={ }_{1}^{0} T \cdot{ }_{2}^{1} T \cdot{ }_{3}^{2} T \ldots \cdot{ }_{i}^{i-1} T \\
& T=\prod_{i=1}^{n}{ }^{i-1} T \\
& { }_{i}^{i-1} T=\left[\begin{array}{cccc}
{ }_{\theta_{\theta_{i}}} & -s_{\theta_{i}} c_{\alpha_{i}} & s_{\alpha_{i}} s_{\alpha_{i}} & a_{i} c_{\theta_{i}} \\
0 & c_{\theta_{i}} c_{\alpha_{i}} & -c_{\theta_{\theta}} s_{\alpha_{i}} & a_{i} s_{\theta_{i}} \\
0 & s_{\alpha_{i}} & c_{\alpha_{i}} & d_{i} \\
0 & 0 & 0 & 1
\end{array}\right]
\end{aligned}
$$

For the calculation of ${ }_{i}^{i-1} T$ DenavitHartenberg parameters must be defined, which are based exclusively on the geometric characteristics of each link and the coordinate systems in each one. 
The characteristics of the parameters are:

ai is the distance from $\mathrm{Xi}-1$ to $\mathrm{Xi}$ along $\mathrm{Xi}$

$\alpha \_i$ is the angle formed from $\mathrm{Xi}$ to $\mathrm{Xi}-1$ around the $\mathrm{Xi}$ axis

di is the distance from $\mathrm{Zi}-1$ to $\mathrm{Zi}$ along $\mathrm{Zi}-1$

$\theta \mathrm{i}$ is the angle formed from $\mathrm{Zi}$ to $\mathrm{Zi}-1$ around the axis $\mathrm{Zi}-1$

The coordinate systems must be placed as in Figure 1, to comply with the characteristics of the parameters mentioned above. Table 1 shows the Denavit-Hartenberg parameters.

\begin{tabular}{|c|c|c|c|c|}
$\boldsymbol{i}$ & $\boldsymbol{a}_{\boldsymbol{i}}$ & $\boldsymbol{\alpha}_{\boldsymbol{i}}$ & $\boldsymbol{d}_{\boldsymbol{i}}$ & $\boldsymbol{\theta}_{\boldsymbol{i}}$ \\
\hline $\mathbf{1}$ & 0 & $-90^{\circ}$ & $-d_{1}$ & $q_{1}$ \\
\hline $\mathbf{2}$ & 0 & $-90^{\circ}$ & $q_{2}$ & 0 \\
\hline $\mathbf{3}$ & $a_{1}$ & 0 & $q_{3}$ & 0 \\
\hline
\end{tabular}

Table 1 Denavit-Hartenberg parameters Source: Own Elaboration

Replacing the values of Table 1 in equation 3 , we obtain:

${ }_{1}^{0} \mathrm{~T}=\left[\begin{array}{cccc}\operatorname{Cos} q_{1} & 0 & -\operatorname{Sen} q_{1} & 0 \\ \operatorname{Sen} q_{1} & 0 & \operatorname{Cos} q_{1} & 0 \\ 0 & -1 & 0 & -d_{1} \\ 0 & 0 & 0 & 1\end{array}\right]$

${ }_{2}^{1} \mathrm{~T}=\left[\begin{array}{cccc}1 & 0 & 0 & 0 \\ 0 & 0 & 1 & 0 \\ 0 & -1 & 0 & q_{2} \\ 0 & 0 & 0 & 1\end{array}\right]$

${ }_{3}^{2} \mathrm{~T}=\left[\begin{array}{cccc}1 & 0 & 0 & a_{1} \\ 0 & 1 & 0 & 0 \\ 0 & 0 & 1 & q_{3} \\ 0 & 0 & 0 & 1\end{array}\right]$

Obtaining the previous matrices, we proceeded to multiply them as equation 1 and 2 explains. The resulting matrix ${ }_{3}^{0} T$, It is the matrix that relates the robot from frame 3 to frame 0 , that is, it relates the end effector of the robot to the base or inertial frame of reference. The equations of the direct kinematic model are as follows:

$r_{11}=\operatorname{Cos} q_{1}$

$r_{21}=\operatorname{Sen} q_{1}$

$r_{31}=0$

$r_{12}=\operatorname{Sen} q_{1}$

$r_{22}=-\operatorname{Cos} q_{1}$

$r_{32}=0$

$r_{13}=0$

$r_{23}=0$ $r_{33}=-1$

$\left.P_{x}=\operatorname{Cos} q_{1} * a_{1}-\operatorname{Sen} q_{1} * q_{2}\right)$

$P_{y}=\operatorname{Sen} q_{1} * a_{1}+\operatorname{Cos} q_{1} * q_{2}$

$P_{z}=-q_{3}-d_{1}$

\section{Inverse kinematics}

The inverse kinematics of a manipulator is a term used to denote the calculation of the joint values of the manipulator, necessary to position a point in space referenced to the manipulator's coordinate system.

There are different ways of approaching this subject, this time it will be developed algebraically.

The last three equations of the direct kinematic model were used. From equation 18 we can solve for the variable $\mathrm{q}_{3}$, which would look like the following equation.

$q_{3}=-P_{z}-1$

Now with equations 16 and 17 we will solve for the variables $\mathrm{q}_{2}$ and $\mathrm{q}_{1}$.

For $\mathrm{q}_{2}$ the following is done, first equations 16 and 17 are squared, the results of equations 20 and 21 are added, for equation 23 we seek to make the equation as simple as possible and finally in equation 24 we clear $q_{2}$.

$P_{x}{ }^{2}=\operatorname{Cos}_{2} q_{1}^{2} a_{1}{ }^{2}-2 \operatorname{Sen} q_{1} q_{2} * \operatorname{Cos} q_{1} a_{1}+$ Sen $q_{1}{ }^{2} q_{2}{ }^{2}$

$P_{y}{ }^{2}=\operatorname{Sen} q_{1}{ }^{2} a_{1}{ }^{2}+2 \operatorname{Sen} q_{1} q_{2} *$

$\operatorname{Cos} q_{1} a_{1}+\operatorname{Cos} q_{1}^{2} q_{2}^{2}$

$P_{x}{ }^{2}+P_{y}{ }^{2}=\operatorname{Cos} q_{1}{ }^{2} a_{1}{ }^{2}+\operatorname{Sen} q_{1}{ }^{2} a_{1}{ }^{2}-$

$2 \operatorname{Sen} q_{1} q_{2} * \operatorname{Cos} q_{1} a_{1}+2 \operatorname{Sen} q_{1} q_{2} *$

$\operatorname{Cos} q_{1} a_{1}+\operatorname{Sen} q_{1}^{2} q_{2}^{2}+\operatorname{Cos} q_{1}^{2} q_{2}^{2}$

$P_{x}^{2}+P_{y}^{2}=a_{1}^{2}+q_{2}^{2}$

$q_{2}=\sqrt{P_{x}^{2}+P_{y}^{2}-a_{1}^{2}}$

For $\mathrm{q}_{1}$, equation 16 is multiplied by the variable $\mathrm{q}_{2}$, the result is seen in equation 25 , this is added with equation 17 , the result is simplified and as a final result in equation 28 the variable is cleared $q_{1}$. 


$$
\begin{aligned}
& -P_{x} q_{2}=-\operatorname{Cos} q_{1} q_{2}+\operatorname{Sen} q_{1} q_{2}^{2} \\
& -P_{x} q_{2}+P_{y}=-\operatorname{Cos} q_{1} q_{2}+ \\
& \operatorname{Cos} q_{1} q_{2}+\operatorname{Sen} q_{1} q_{2}^{2}+\operatorname{Sen} q_{1} \\
& -P_{x} q_{2}+P_{y}=\operatorname{Sen} q_{1}\left(q_{2}^{2}+1\right) \\
& q_{1}=\operatorname{Sen}^{-1}\left(\frac{P_{y}-P_{x} q_{2}}{\left(1+q_{2}^{2}\right)}\right)
\end{aligned}
$$

In the previous equation $\mathrm{q}_{1}$ remains in inverse sine function, however there is the possibility of changing it to inverse cosine function. For this, equation 17 is multiplied by the variable $\mathrm{q}_{2}$, the result is seen in equation 29 , this is added with equation 16 , what is obtained is simplified and as a final result in equation 32 the variable is cleared $q_{1}$.

$$
\begin{aligned}
& P_{y} q_{2}=\operatorname{Sen} q_{1} q_{2}+\operatorname{Cos} q_{1} q_{2}^{2} \\
& P_{y} q_{2}+P_{x}=-\operatorname{Sen} q_{1} q_{2}+\operatorname{Sen} q_{1} q_{2}+ \\
& \operatorname{Cos} q_{1} q_{2}^{2}+\operatorname{Cos} q_{1} \\
& P_{y} q_{2}+P_{x}=\operatorname{Cos} q_{1}\left(q_{2}^{2}+1\right) \\
& \frac{P_{y} q_{2}+P_{x}}{\left(q_{2}^{2}+1\right)}=\operatorname{Cos} q_{1}
\end{aligned}
$$

\section{Kinematic Model Check}

By having the matrix ${ }_{3}^{0} T$, the check was carried out to affirm that the resulting matrix obtained is correct and describes mathematically and correctly the RPP robot.

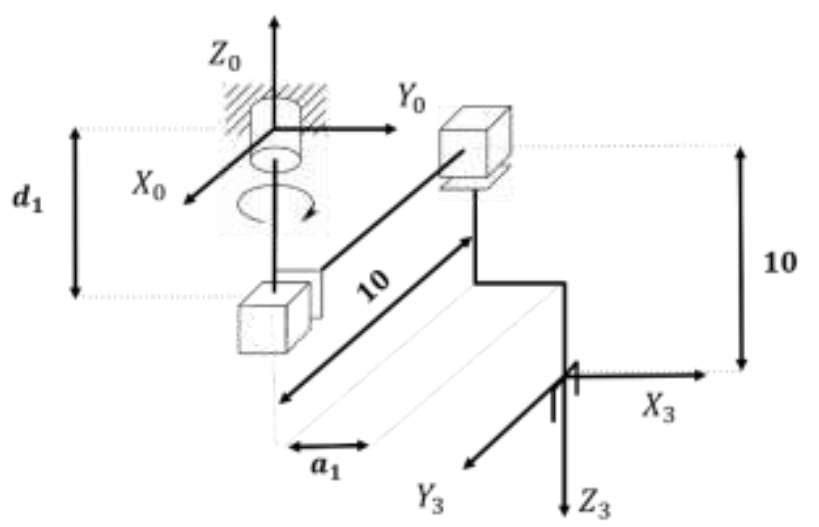

Figure 2 Positioning example

Source: Own Elaboration

$$
q^{T}=\left[\begin{array}{lll}
90^{\circ} & 10 & 10
\end{array}\right]
$$

With the equations from 7 to 18 we can deduce the following equation:

$$
{ }_{3}^{0} \mathrm{~T}=\left[\begin{array}{cccc}
0 & 1 & 0 & -10 \\
1 & 0 & 0 & a_{1} \\
0 & 0 & -1 & -10-d_{1} \\
0 & 0 & 0 & 1
\end{array}\right]
$$

In case of checking visually, equation 34 would be obtained.

On the other hand, checking the inverse model, the position vector of Figure 1 is provided.

Position vector $\vec{P}=\left[\begin{array}{c}1 \\ 10 \\ -11\end{array}\right]$ (35). It was solved for the variables with equations 19, 24 and 32 .

$$
\begin{aligned}
& q_{3}=-(-11)-1=10 \\
& q_{2}=10 \\
& q_{1}=0^{\circ}
\end{aligned}
$$

\section{Dynamic model}

The dynamic model of a robotic system helps to know the torque and forces required for it to move to a point. There are different methods to arrive at the dynamic model, however on this occasion it was decided to use Jacobian.

It began by obtaining the matrices that relate the reference frame 0 with each of the centers of mass, Table 2 shows the DenavitHartenberg parameters for the centers of mass..

\begin{tabular}{|c|c|c|c|c|}
\hline $\boldsymbol{i}$ & $\boldsymbol{a}_{\boldsymbol{i}}$ & \multicolumn{1}{c|}{$\boldsymbol{\alpha}_{\boldsymbol{i}}$} & $\boldsymbol{d}_{\boldsymbol{i}}$ & $\boldsymbol{\theta}_{\boldsymbol{i}}$ \\
\hline$c m_{1}$ & 0 & 0 & $-c m_{1}$ & $q_{1}$ \\
\hline$c m_{2}$ & 0 & 0 & $q_{2}-l_{2}$ & 0 \\
\hline$c m_{3}$ & $l_{1}$ & 0 & $\left(q_{3}-l_{3}\right)$ & 0 \\
\hline
\end{tabular}

Table 2 Denavit-Hartenberg Parameters for Centers of Mass

Source: Own Elaboration

Replacing the values from Table 2 in equation 3 , we obtain:

$$
\begin{aligned}
{ }_{c m_{1}} \mathrm{~T}^{\mathrm{T}} & =\left[\begin{array}{cccc}
C_{1} & -S_{1} & 0 & 0 \\
S_{1} & C_{1} & 0 & 0 \\
0 & 0 & 1 & -c m_{1} \\
0 & 0 & 0 & 1
\end{array}\right] \\
{ }_{c m_{2}} \mathrm{~T} & =\left[\begin{array}{cccc}
C_{1} & 0 & -S_{1} & -S_{1}\left(q_{2}-l_{2}\right) \\
S_{1} & 0 & C_{1} & C_{1}\left(q_{2}-l_{2}\right) \\
0 & -1 & 0 & -d_{1} \\
0 & 0 & 0 & 1
\end{array}\right]
\end{aligned}
$$


${ }_{c m}^{0} \mathrm{~T}=\left[\begin{array}{cccc}C_{1} & S_{1} & 0 & C_{1} l_{1}-S_{1} q_{2} \\ S_{1} & -C_{1} & 0 & S_{1} l_{1}+C_{1} q_{2} \\ 0 & 0 & -1 & -\left(q_{3}-l_{3}\right)-d_{1} \\ 0 & 0 & 0 & 1\end{array}\right]$

The Jacobians were then calculated for each center of mass by means of the partial derivative of the joint position according to equation 42 .

$$
J_{v c m_{i}}=\left[\begin{array}{ccc}
\frac{d}{d q_{1}}\left(P_{x} c m_{i}\right) & \frac{d}{d q_{2}}\left(P_{x} c m_{i}\right) & \ldots \frac{d}{d q_{n}}\left(P_{x} c m_{i}\right) \\
\frac{d}{d q_{1}}\left(P_{y} c m_{i}\right) & \frac{d}{d q_{2}}\left(P_{y} c m_{i}\right) & \ldots \frac{d}{d q_{n}}\left(P_{y} c m_{i}\right) \\
\frac{d}{d q_{1}}\left(P_{z} c m_{i}\right) & \frac{d}{d q_{2}}\left(P_{z} c m_{i}\right) & \ldots \frac{d}{d q_{n}}\left(P_{z} c m_{i}\right)
\end{array}\right]
$$

With equation 43 the angular velocity of the frame of reference was obtained at the $\mathrm{i}$-th center of mass

$$
{ }_{i}^{0} \omega=\rho_{1} \cdot \overrightarrow{z_{0} q_{(1)}} \cdots+\rho_{n} \cdot{ }_{i-1}^{0} R(t) \overrightarrow{Z_{l-1}} q_{(l)}
$$

Where:

$$
\rho=\left\{\begin{array}{c}
1 \text { for revolutionary union } \\
0 \text { for prismatic junction }
\end{array}\right\}
$$

With the above in a generalized way for the $n$-th frame of reference, equation 43 was rewritten as follows:

$$
{ }_{n}^{0} \omega=\left[\begin{array}{llll}
\rho_{1} \overrightarrow{z_{0}} & \rho_{21}{ }^{0} R(t) \overrightarrow{z_{1}} & \cdots & \rho_{n n-1}{ }^{0} R \\
(t) & \overrightarrow{z_{n-1}}
\end{array}\right]\left[\begin{array}{c}
\dot{q_{(1)}} \\
\dot{q_{(2)}} \\
\vdots \\
\dot{q_{(n)}}
\end{array}\right]
$$

Where

$$
J_{w_{n}}=\left[\begin{array}{llll}
\rho_{1} \overrightarrow{z_{0}} & \rho_{21} R_{(t)} \overrightarrow{z_{1}} & \cdots & \rho_{n n-1} R_{(t)} \overrightarrow{z_{n-1}}
\end{array}\right]
$$

It is known as the Jacobian of angular velocity for a robot that has prismatic joints and that is revolutionary in its structure.

With the above, the following results were obtained:

$$
\begin{aligned}
J_{v c m 1} & =\left[\begin{array}{lll}
0 & 0 & 0 \\
0 & 0 & 0 \\
0 & 0 & 0
\end{array}\right] \\
J_{w c m 1} & =\left[\begin{array}{lll}
0 & 0 & 0 \\
0 & 0 & 0 \\
1 & 0 & 0
\end{array}\right] \\
J_{v c m 2} & =\left[\begin{array}{ccc}
-\left(C_{1}\right)\left(q_{2}-l_{2}\right) & -S_{1} & 0 \\
-\left(S_{1}\right)\left(q_{2}-l_{2}\right) & C_{1} & 0 \\
0 & 0 & 0
\end{array}\right]
\end{aligned}
$$

$$
\begin{aligned}
J_{w c m 2} & =\left[\begin{array}{lll}
0 & 0 & 0 \\
0 & 0 & 0 \\
0 & 0 & 0
\end{array}\right] \\
J_{v c m 3} & =\left[\begin{array}{ccc}
-\left(l_{1} S_{1}+C_{1} q_{2}\right) & -S_{1} & 0 \\
\left(l_{1} C_{1}-S_{1} q_{2}\right) & C_{1} & 0 \\
0 & 0 & -1
\end{array}\right] \\
J_{w c m 3} & =\left[\begin{array}{lll}
0 & 0 & 0 \\
0 & 0 & 0 \\
0 & 0 & 0
\end{array}\right]
\end{aligned}
$$

For the calculation of the inertia matrix, equation 53 is used.

$$
\begin{aligned}
D & =\sum_{i=1}^{3}\left(m_{i} J_{v_{c m_{i}}}^{T} J_{v_{c m_{i}}}+J_{\omega_{i}}^{T} R_{i-0}^{0} I R_{i-0}^{0}{ }^{T} J_{\omega_{i}}\right) \\
D & =\left[\begin{array}{lll}
D_{11} & D_{12} & D_{13} \\
D_{21} & D_{22} & D_{23} \\
D_{31} & D_{32} & D_{33}
\end{array}\right]
\end{aligned}
$$

$D_{11}=I_{z z}+m_{2} q_{2}{ }^{2}-2 m_{2} l_{2} q_{2}+m_{2} l_{2}{ }^{2}+$ $m_{3} l_{1}{ }^{2}+m_{3} q_{2}{ }^{2}$.

$D_{12}=l_{1} m_{3}$.

$D_{13}=0$.

$D_{21}=l_{1} m_{3}$.

$D_{22}=m_{3}+m_{2}$.

$D_{23}=0$.

$D_{31}=0$.

$D_{32}=0$.

$D_{33}=m_{3}$

The Christoffel symbols were used to calculate the Coriolis matrix

$$
\begin{aligned}
& c_{i, j, k}=\frac{1}{2}\left\{\frac{\partial d k j}{\partial i}+\frac{\partial d k i}{\partial j}-\frac{\partial i j}{\partial k}\right\} \\
& C_{k j}=\sum_{i=1}^{n}\left(c_{i j k} \dot{q}_{i}\right) \\
& C=\left[\begin{array}{lll}
C_{11} & C_{12} & C_{13} \\
C_{21} & C_{22} & C_{23} \\
C_{31} & C_{32} & C_{33}
\end{array}\right]
\end{aligned}
$$

The results using equation 46 substituting with equation 55 are as follows:

$$
\begin{aligned}
& C_{111}=C_{113}=C_{122}=C_{123}=C_{131}= \\
& C_{132}=C_{133}=C_{212}=C_{213}=C_{221}= \\
& C_{222}=C_{223}=C_{231}=C_{232}=C_{233}= \\
& C_{311}=C_{312}=C_{313}=C_{321}=C_{322}= \\
& C_{323}=C_{331}=C_{332}=C_{333}=0 \\
& C_{112}=-m_{2} q_{2}+m_{2} l_{2}-m_{3} q_{2} \\
& C_{121}=m_{2} q_{2}-m_{2} l_{2}+m_{3} q_{2} \\
& C_{211}=m_{2} q_{2}-m_{2} l_{2}+m_{3} q_{2}
\end{aligned}
$$


Finally, the gravity vector was obtained through the partial derivative of the potential energy.

$g=\frac{\partial E_{P_{T}}}{\partial q_{i}}$

The potential energy of our robot is shown in the following equation:

$$
\begin{aligned}
& E_{P_{T}}=m_{1} g\left(-C m_{1}\right)+m_{2} g\left(-d_{1}\right)+ \\
& m_{3} g\left(-d_{1}-q_{3}+l_{3}\right)
\end{aligned}
$$
follows:

Therefore, the gravity vector was as

$g\left[\begin{array}{c}0 \\ 0 \\ -m_{3}\end{array}\right]$

Result of the dynamic model by Jacobians.

$$
\begin{aligned}
& D(q) \ddot{q}+C(q, \dot{q}) \dot{q}+g(q)=\tau \\
& {\left[\begin{array}{l}
\tau_{1} \\
f_{2} \\
f_{3}
\end{array}\right]=\left[\begin{array}{lll}
d_{11} & d_{12} & d_{13} \\
d_{21} & d_{22} & d_{23} \\
d_{31} & d_{32} & d_{33}
\end{array}\right]\left[\begin{array}{l}
\ddot{q}_{1} \\
\ddot{q}_{2} \\
\ddot{q}_{3}
\end{array}\right]+} \\
& {\left[\begin{array}{lll}
c_{11} & c_{12} & c_{13} \\
c_{21} & c_{22} & c_{23} \\
c_{31} & c_{32} & c_{33}
\end{array}\right]\left[\begin{array}{l}
\dot{q}_{1} \\
\dot{q}_{2} \\
\dot{q}_{3}
\end{array}\right]+g\left[\begin{array}{l}
g 11 \\
g 22 \\
g 33
\end{array}\right]}
\end{aligned}
$$

Substituting the results in equation 64:

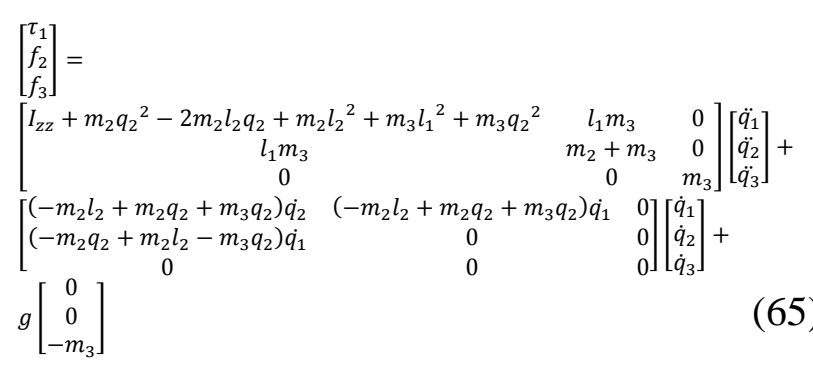

The following system was implemented in Simulink, using the dynamic model of the robot obtained in the previous section.

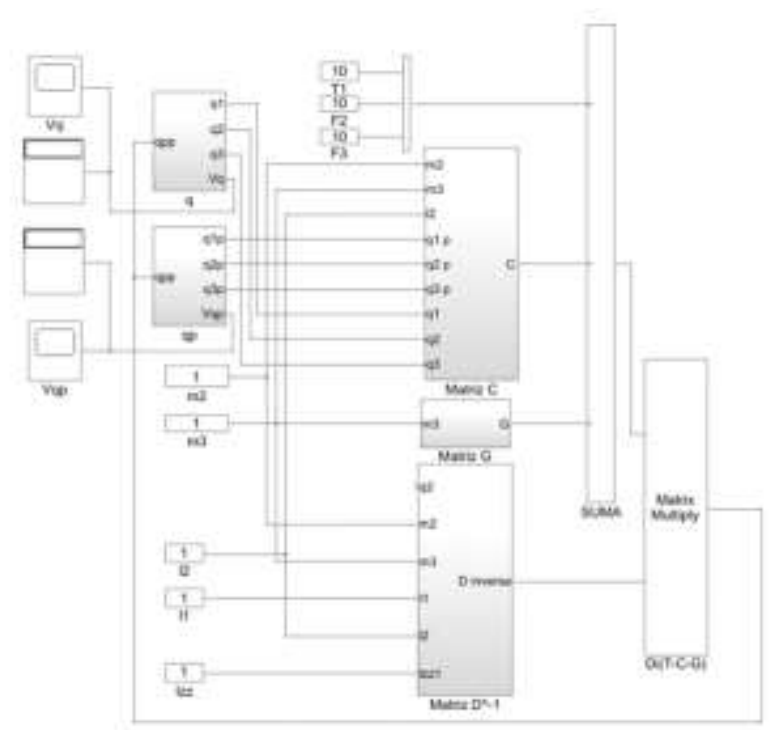

Figure 3 Dynamic model in Simulink Source: Own Elaboration

The tests were carried out, with the values shown in Table 3.

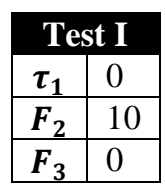

Table 3 Test Parameters I

Source: Own Elaboration

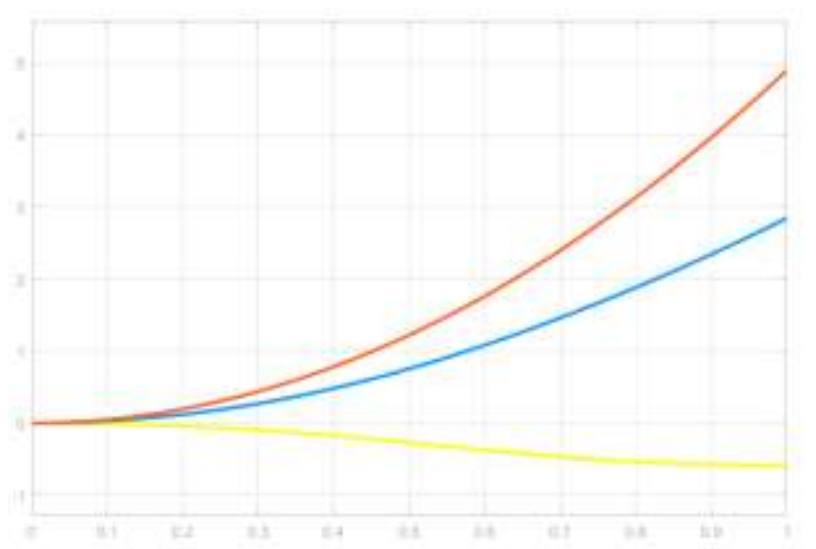

Graphic 1 Resutss Parameters I

Source: Own Elaboration

The red curve shows the displacement of $\mathrm{q}_{3}$, the yellow of $\mathrm{q}_{1}$ and finally the blue of $q_{2}$.

The reason why $\mathrm{q}_{3}$ has a displacement is because a force is not applied, remembering the equation in the dynamic model, it is appreciated that, by not applying external torque, $\left(\mathrm{q}_{3}\right)^{\text {" }}$ has a value of 0 , then gravity acts which causes it to have a displacement. 
It can be seen that $\mathrm{q}_{2}$ has a displacement and it is because a force is being applied to it. On the other hand, $\mathrm{q}_{1}$ has a slight displacement despite not having an applied torque, it is because when a force is applied to link two, it has a contrary reaction that is applied to link 1 . Table 4.

The values used for test e are shown in

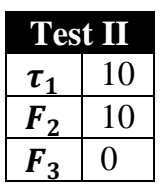

Table 4 Test Parameters II

Source: Own Elaboration

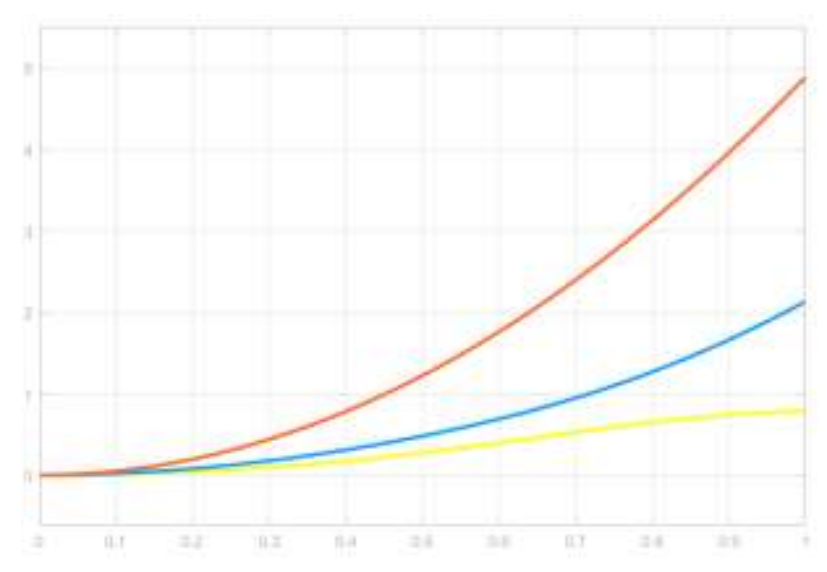

Graphic 2 Test results II

Source: Own Elaboration

The results of test 2 are shown in Graphic 2. In this case the red color is the displacement of $\mathrm{q}_{3}$, the yellow of $\mathrm{q}_{1}$ and finally the blue of $\mathrm{q}_{2}$.

Unlike the previous test, torque 1 was taken equal to 10 Newtons, which makes q_1 have a displacement and force 2 makes $\mathrm{q}_{2}$ have it, finally $\mathrm{q}_{3}$ falls due to gravity.

\section{Results}

The results obtained with respect to forward kinematics and inverse kinematics are described below.

- $\quad$ Equations 16 to 18 show the value of the $\mathrm{x}, \mathrm{y}, \mathrm{z}$ coordinates of the end point of the manipulator with respect to the zero reference system.

- Equations 19, 24, 28 and 32 show the equations to obtain the value of the values that each of the robot's joints will have.

- Equation 55 shows the final dynamic model of the robot.
- Figures 1 and 2 show the results of the model simulation.

\section{Conclusions}

The mathematical models and their respective simulations of manipulative robots were carried out. To make it more didactic, the examples showed that the results are mathematically correct. With these results, it is possible to start a control to follow trajectories or integrate a sensory system. This shows that with the help of current literature, numerous structures can be made, however, it is sometimes difficult to understand and it is necessary to show examples with their mathematical development and simulation to make learning and development easier. types of manipulators included in an automation area.

\section{References}

Algarín-Pinto, J.A., Aguilera-Hernández, M.I., Ortiz-Salazar, M., Ortiz-Simón, J.L., Rojo-

Craig, J. J. (2004). Introduction to Robotics: Mechanics and Control (3rd ed.). Pearson.

http://ecorfan.org/taiwan/research_journals/Sim ulacion_Computacional/vol2num4/Revista_de Simulaci\%C3\%B3n_Computacional_V2_N4_1 .pdf

Mejía-Calderón, L. A., González-Echeverry, A., \& Quintero-Riaza, H. F. (2017). Cinemática inversa de un robot redundante tipo scorbot - ER Vplus: influencia de índices de desempeño. $\begin{array}{lll}\text { ITECKNE, } & 14(1),\end{array}$ https://doi.org/10.15332/iteckne.v14i1.1627

Ortiz Simón, J. L., Minor Martínez, A., Ordorica Flores, R., Limón Aguilar, J. L., \& Suaste, E. (2011). Kinematic fundamentals of $a$ biomechatronic laparoscopy system. The International Journal of Medical Robotics and Computer Assisted Surgery, 7(3), n/a. https://doi.org/10.1002/rcs.395

Spong, M. W., Hutchinson, S., \& Vidyasagar, M. (2005). Robot Modeling and Control. Wiley. Velázquez, G., Programa simulador de efectos de cambios de masa y longitud de eslabones en modelo dinámico y cinemático de brazo manipulador de Gdl, 